\title{
An Evaluation of a Fourth Level English Textbook Used in Secondary Schools in Riyadh City
}

\author{
Yusuf Ahmad K. Alsulami ${ }^{1}$ \\ ${ }^{1}$ Ministry of Education, King Saud University, Kingdom of Saudi Arabia \\ Correspondence: Yusuf Ahmad K. Alsulami, Ministry of Education, King Saud University, Kingdom of Saudi \\ Arabia. \\ Received: January 17, 2021 \\ Accepted: January 29, 2021 \\ Online Published: February 1, 2021 \\ doi: 10.5539/elt.v14n2p68 \\ URL: https://doi.org/10.5539/elt.v14n2p68
}

\begin{abstract}
This paper evaluates a textbook called Traveller 4 that is used in the second grade of secondary schools in Riyadh City, Saudi Arabia, considering its general appearance and design, objectives, content, social and cultural contexts, tasks and activities, and usefulness for developing language skills. The paper also reviews the literature concerning textbook evaluation, referring to various theoretical and empirical studies that have contributed to the field of educational material evaluation. The research used a descriptive research model to assess data regarding the assessment of the English textbook and employed a questionnaire to investigate teachers' perspectives on a range of related items. The questionnaire targeted high school English teachers in Riyadh city and consisted of 40 items, which were divided into six categories. The instrument used in this study to evaluate Traveller 4 was the ESL Textbook Evaluation Checklist. The findings of this research study revealed important points relating to the characteristics of a good textbook and identified strengths, weaknesses, and opportunities to modify the book. This paper concludes with recommendations for improving the textbook.
\end{abstract}

Keywords: evaluation, English textbook, fourth level, secondary schools

\section{Introduction}

Saudi Arabia is one of the developing countries that strives, using all possible means, to elevate and improve its education system. The Saudi government considers education an investment for the future and spares no effort or money in supporting human development, which is seen as the key to advancement (Al-Salloom, 1995; Al-Sweel, 1993; Centre for Statistical Data and Educational Documentation [CSDED], 1996). The Ministry of Education in Saudi Arabia, among many other programs, provides for the teaching of English as a foreign language (EFL) in its schools.

This study evaluated a textbook called Traveller 4 that is used in the second grade of secondary schools in Riyadh City, considering its general appearance and design, objectives, content, social and cultural contexts, tasks and activities, and usefulness for developing language skills. The researcher also paid close attention to the syllabus and the methodologies employed in it. Since this textbook constitutes an introduction to English for Saudi students, it is important for the textbook to be engaging enough to excite the students' interest, but also to thoroughly present the fundamentals of English in an age-appropriate manner, which made the evaluation of the textbook a matter of high importance. The English language textbook was designed by MM Publications and introduced by Tatweer Company for Educational Services in 2012.

The researcher was confident that evaluating the authoritativeness of Traveller 4 as an English textbook for Riyadh's secondary schools was a worthwhile project that would lead to the future success of English language programs and potentially help teachers to determine its value.

\subsection{Significance of the Study}

When taking an action, we should first consider its purpose. Traveller 4 helps students to develop English language skills during their EFL learning; hence the significance of this study lies in the textbook's recent publication (at the time of the study) and the need to evaluate it and provide feedback.

According to Weir and Roberts (1994), there are two main reasons for evaluating teaching materials. First, it provides evidence "which can inform theoretical disputes about directions to be followed in language teaching or 
in teacher education." Second, it is a tool for indicating the suitability of particular approaches or techniques under given conditions and determining whether they meet the claims made for them.

Moreover, the study aimed, based on a survey, to help teachers decide the best items for evaluating textbooks. Since teachers are always at the forefront of educational developments, the study would benefit them by providing feedback on the textbook and how it can be developed in the future.

\subsection{Statement of the Problem}

The publication of a new English textbook is always welcome, but it is vital to evaluate it if it is intended for use by second grade secondary school students, because it should make the learning of EFL more enjoyable, stimulating, and success-oriented, enabling students to reach the point at which they can express themselves in English.

\subsection{Purpose of the Study}

The purpose of this study was to evaluate the English textbook Traveller 4 for use in Riyadh's secondary schools, since it had recently been released. The researcher chose to evaluate this textbook for two reasons: first, it provided the basic material for English language programs in Saudi schools and, second, it was a new book series, the evaluation of which was an educational necessity. The study's research questions fell into six categories:

- General appearance and design

- Objectives

- Content

- Social and cultural contexts

- Language skills

- Tasks and activities

\section{Literature Review}

This section reviews the literature relating to textbook evaluation and considers various theoretical and empirical studies that have contributed to the field of educational materials evaluation.

In recent years, the quality of education in many countries has been of national concern. The three major pillars of education (student achievement, teacher proficiency, and curricula) have thus been investigated to identify the factors that affect student achievement and/or lead to a state of dissatisfaction with events in education (Al-Hamid, 1998; Al-Rasheed, 1998; Al-Shahrani, 1996).

Many scholars have emphasized the role of curriculum evaluation as the key to curriculum development and hence to better education. Patton (1990) emphasized that the quality of a program is the major concern in program evaluation. He defined "quality" not only as the "attributes of the program" (p. 108), but also as the "quality of life experienced by the participants of the program" (p. 109). He contended: "Program evaluation focuses on the overall program" (p. 110).

Tomlinson (2003) claimed that "materials development is both a field of study and a practical undertaking" (p. 1). In program evaluation, it is often necessary to describe or explain the rationale for how a program should function to achieve its goals and objectives and, since the literature on language teaching materials is vast, the researcher selected the most appropriate.

\subsection{Theoretical Background}

Richards (2001) stated that, without textbooks, a program may have no impact; therefore, textbooks should provide structure and support a syllabus. Additionally, the use of a textbook in a program can guarantee that students in different classes will receive similar content and, therefore, can be evaluated in the same way; in other words, textbooks provide the standards for instruction. Moreover, including a variety of learning resources, such as workbooks, CDs, videos, and similar, can make the learning environment more interesting and enjoyable for the learners.

Ellis (1997) suggested that textbook evaluation helps teachers to go beyond impressionistic assessments and acquire useful, accurate, systematic, and contextual insights into the overall nature of textbook material.

Ellis (1997) distinguished two types of materials evaluation: predictive and retrospective. "A predictive evaluation is designed to support decisions regarding what materials to use. Teachers who are required to carry out a predictive evaluation determine which materials are best suited to their purposes. Once the materials have 
been used, further evaluation may be conducted to find out whether the materials have been effective, and this type of evaluation is called retrospective evaluation. According to the aforementioned definitions, both predictive and retrospective evaluations aim to make the teaching/learning environment more effective." Both types of evaluation help teachers to make appropriate judgments concerning the effectiveness of their teaching, including the materials they use.

The reasons for materials evaluation activities are also many and varied. One of the major reasons is the need to adopt new course books. Another reason, as Cunningsworth (1995) emphasized, is to identify the particular strengths and weaknesses of course books that are already in use. Such activities permit teachers to make optimum use of their strong points and strengthen the weaker areas by adapting and substituting materials from other books. Course book analyses and evaluations not only support teachers in developing themselves, but also provide them with useful insights into the nature of the material. Moreover, as Hutchinson (1987) pointed out, materials evaluation serves the immediate practical aim of selecting teaching materials and plays a critical role in developing teachers' awareness in some ways; that is, by allowing teachers to analyze their own presuppositions about the nature of language and learning, encouraging teachers to establish prerequisites, and helping them to see materials as an essential part of the whole teaching/learning situation.

\subsection{Empirical Studies on Textbook Evaluation}

Many empirical studies have been carried out on textbook evaluation in different contexts, with different researchers using various textbook evaluation schemes or checklists to evaluate textbooks or materials. In South Korea, for example, Litz (2005) investigated the appropriateness of a textbook called English Firsthand 2 (EF2), which was used by Sung Kyun Kwan University in Suwon, South Korea. He concluded that, while EF2 was not as well-known as other prominent series of textbooks, it had many notable and worthwhile characteristics; for example, the entire textbook was well conceived and had a variety of useful supplementary materials. The book was found to be attractive, with clear, logical, and coherent organization. Additionally, it integrated the four language skills without neglecting other important English Language Teaching issues, such as vocabulary development. Despite its strengths, Litz found that EF2 still contained repetitive activities that failed to encourage truly meaningful practices, promote realistic discourse, or facilitate the internalization of the language.

Habtoor (2012) conducted a study to evaluate First Class: English for Tourism, as an English for Specific Purposes (ESP) textbook taught to the sophomore students of Tourism and Archaeology at King Saud University, Riyadh, Saudi Arabia. The study revealed the opinions of the teachers on the textbook regarding its components, its practicality, its activities, the language type, the subject, the content, the four major language skills, the sub-skills of grammar and vocabulary and how they are offered. It also investigated the suitability of the book regarding the learners' level and their needs. The results revealed that the textbook matches the teachers' expectations about their students' progression in learning in the Saudi Arabian context. In addition the results showed that there was a harmony among the teachers on the suitability of the textbook.

Tok (2010) evaluated the Spot On textbook used in state primary schools in Turkey. The researcher concluded that it had both positive and negative characteristics. In terms of the positive features, the teacher's book contained guidance about using the textbook for the greatest benefit of students. The content of the textbook was generally realistic, interesting, challenging, and motivating, with activities incorporating both pair and group work. As Tok (2010) indicated, the subject and content of the textbook varied sufficiently, was not culturally biased, and did not contain any negative stereotyping. Despite its strengths, Spot On had many negative characteristics. Most respondents to Tok's (2010) survey responded unfavorably to the layout and design of the book and believed that the activities in the textbook did not encourage sufficient communicative and meaningful practices.

Al-Jaser (1988) conducted a comparative study to evaluate two versions of an English language textbook used in first grade boys' and girls' secondary schools, respectively, in Saudi Arabia. Both English language teachers and their supervisors participated in the study, which used a questionnaire of 73 items as a research instrument, built on the following categories:

1. Textbook introduction
A. the target audience
B. the grounded theory of the textbook
C. the objectives of the course
D. teacher's guidelines 
2. Textbook content
A. the subject matter and concepts of the textbook
B. the textbook's language and style
C. aids

The findings of Al-Jaser's (1988) study can be summarized as follows:

1. The evaluated textbooks did not meet all the criteria for a good textbook.

2. The degree of adherence to some criteria for a good textbook was not as strong as it should be.

3. The boys' and girls' books were very similar.

The researcher explained the strengths and weaknesses of the two books and recommended that these textbooks should be revised according to the students' gender, level, needs, and further responsibilities.

Ereksoussy (1993) conducted qualitative research to evaluate a textbook used at that time to teach first-year female students in intermediate schools in Saudi Arabia. She used a 126-item checklist to determine the criteria for her evaluation, which consisted of six main categories:

\section{Objectives}

2. Content selection

3. Gradation and recycling

4. Presentation frames

5. Practice activities (drills and exercises)

6. Assessment models (model tests)

Ereksoussy (1993) found that there was more correspondence to than divergence from the criteria for a good textbook. The percentage of adherence to the criteria was $82.38 \%$, and the researcher made recommendations and suggestions for further improvement.

\section{Methodology}

This chapter describes the research methodology of this study; it also describes the materials, the participants, the questionnaire, the data collection instruments, and the procedures.

\subsection{Research Method and Questions}

This research used a descriptive research model to assess the English textbook (Traveller 4) used in the second grade of secondary schools in Riyadh City second semester in 2016. The specific research questions related to the textbook's effectiveness in terms of:

1. General appearance and design

\section{Objectives}

3. Content

4. Social and cultural contexts

5. Language skills

6. Tasks and activities

\section{Materials}

The Traveller 4 textbook selected for evaluation was designed by MM Publications and introduced by Tatweer Company for Educational Services in 2012. It was used for teaching English in secondary schools for three hours per week. It included seven chapters, five of which were required and two optional. Each chapter consisted of six sections: reading, writing, speaking, listening, grammar, and vocabulary.

\subsection{Study Participants}

The participants of this study were teachers who used Traveller 4 textbooks to teach English in Male secondary schools in Riyadh City.

\subsection{The Questionnaire}

A questionnaire was employed to investigate teachers' points of view regarding basic items. The questionnaire consisted of 40 items, which were divided into the six categories mentioned previously. 


\subsection{Data Collection Instruments}

A checklist instrument was used for the textbook evaluation. A survey questionnaire was used to evaluate Traveller 4. This is one of the common tools used to conduct a survey, since it is easy to administer and can gather sufficient information if it is properly constructed. The Statistical Package for Social Sciences (SPSS) program was used to analyze the data from the questionnaire.

\subsection{Procedures}

In this descriptive study, the quantitative data were obtained through the teacher EFL Textbook Evaluation Checklist.

The data collection procedures took about three weeks. The data were collected from male English language teachers who were randomly selected during the second semester of the 2016 academic year. Before introducing the instrument, the researcher informed the participants of the purpose of the study and the data collection procedure. Necessary information was given to them, and the dates for the data collection were scheduled according to the teachers' teaching timetables in randomly selected high schools. The collected data were entered into SPSS for further analysis. Descriptive statistics, including means, standard deviations, frequencies, and percentages, were used for the data analysis.

\section{Results and Discussion}

This chapter presents the analyses of the data and the results of the survey, which aimed to assess the textbook from the male teachers' perspectives. The evaluation focused on six criteria: general appearance and design, objectives, content, social and cultural contexts, language skills and, finally, tasks and activities. The means, standard deviations, and percentages for items were calculated to describe and summarize the responses of the teachers. The results for the items that related to each evaluation criterion are presented in tables in the subsequent text, with corresponding explanations.

The first research question asked: "To what extent is the textbook effective according to the general appearance and design of the book?" Responses were measured through five items in the questionnaire, and the responses are presented in Table 1.

Table 1. Means, standard deviations, frequencies, and percentages for the items relating to (A) general appearance and design

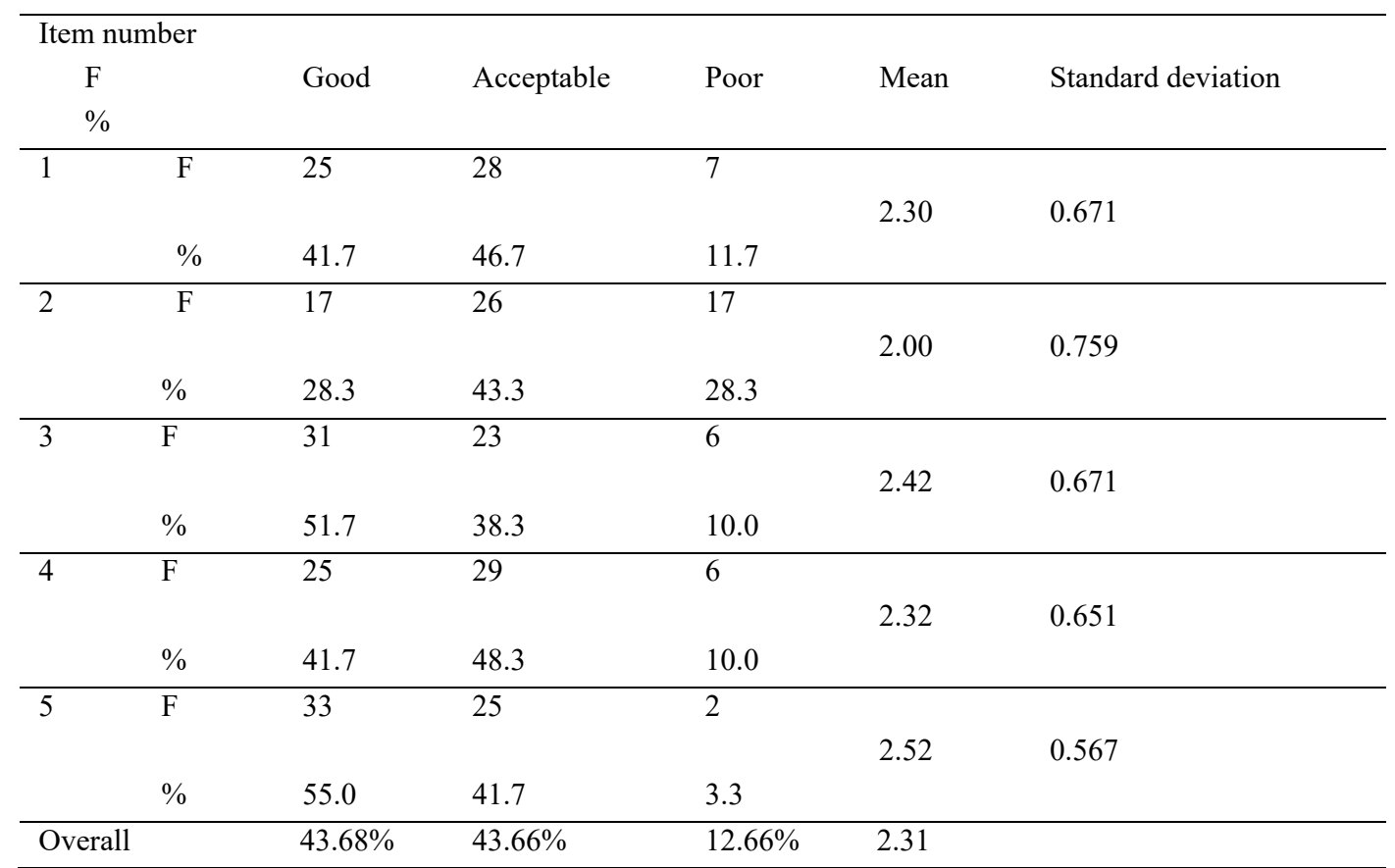

The general appearance and design of the textbook were assessed by asking whether the book was attractive, its size was appropriate, it had a title at the beginning of each subject, the illustrations were simple, and the illustrations were colored. The results of the evaluation survey are shown in Table 1, which clearly indicates that most of the respondents (46.7\%) believed the book was largely unattractive, but saw it as "acceptable"; however, 
$41.7 \%$ believed it was attractive and would attract students, while only $11.7 \%$ said the book was so "poor" and unattractive that could not support this statement.

In relation to the book's size, almost $43.3 \%$ of the teachers chose "acceptable" as their response and said it was reasonably appropriate, while two groups with the same percentages $(28.3 \%)$ chose the options "good" and "poor".

Regarding the next item, $51.7 \%$ of the respondents liked the book because it had a title at the beginning of each subject, which they appreciated, and 38.3\% said the book's general appearance was "acceptable" because it had a title at the beginning of each subject. Only $10 \%$ did not agree with the statement and said it that the book was "poor" for not providing a title at the beginning of each subject.

Regarding illustrations, $48.3 \%$ of the respondents believed they were simple and most chose the option "acceptable". Roughly $41.7 \%$ chose the option "good" and liked the simplicity of the illustrations in the book, while $10 \%$ did not like the illustrations and thought their simplicity was "poor".

The last item in this section concerned colored illustrations, and 55\% of the respondents liked the book's colored illustrations, $41.7 \%$ said they were "acceptable," and only 3.3\% thought the colored illustrations were inadequate.

The second research question asked about the extent to which the textbook was effective according to its objectives. This was measured through five items in the questionnaire, and the responses are presented in Table 2 .

Table 2. Means, standard deviations, frequencies, and percentages for the items regarding (B) objectives

\begin{tabular}{|c|c|c|c|c|c|c|}
\hline \multicolumn{7}{|c|}{ Item number } \\
\hline \multicolumn{2}{|c|}{$\mathrm{F}$} & Good & Acceptable & Poor & Mean & Standard deviation \\
\hline \multicolumn{7}{|c|}{$\%$} \\
\hline \multirow[t]{3}{*}{1} & $\mathrm{~F}$ & 23 & 23 & 14 & & \\
\hline & & & & & 2.15 & 0.777 \\
\hline & $\%$ & 38.3 & 38.3 & 23.3 & & \\
\hline \multirow[t]{3}{*}{2} & $\mathrm{~F}$ & 14 & 28 & 18 & & \\
\hline & & & & & 1.93 & 0.733 \\
\hline & $\%$ & 23.3 & 46.7 & 30.0 & & \\
\hline \multirow[t]{3}{*}{3} & $\mathrm{~F}$ & 11 & 19 & 30 & & \\
\hline & & & & & 1.68 & 0.770 \\
\hline & $\%$ & 18.3 & 31.7 & 50.0 & & \\
\hline \multirow[t]{3}{*}{4} & $\mathrm{~F}$ & 9 & 23 & 28 & & \\
\hline & & & & & 1.68 & 0.725 \\
\hline & $\%$ & 15.0 & 38.3 & 46.7 & & \\
\hline \multicolumn{2}{|c|}{ Overall } & $23.72 \%$ & $38.75 \%$ & $37.50 \%$ & 1.86 & \\
\hline
\end{tabular}

The objectives of the textbook were assessed by asking whether the objectives were clear, measurable, achievable, and met students' needs. The results for these items are shown in Table 2 and clearly indicate that the objectives played an important role in evaluating the textbook.

Most teachers thought that the objectives were "good" or "acceptable", with the same percentages (38.3\%), while the last group $(23.3 \%)$ chose "poor", claiming that the objectives were unclear and they had difficulty in understanding them.

$46.7 \%$ of the teachers said the objectives were "acceptable" for their measurability, while $30 \%$ believed they were "poor" and unmeasurable; however, $23.3 \%$ of the teachers said the objectives were measurable.

For the next item, around $50 \%$ of the teachers did not support this statement, believing that the objectives were not achievable by the end of the semester; $31.7 \%$ said they were "acceptable" and some could be achieved; but only $18.3 \%$ believed they were "good" and achievable by the end of the semester.

The highest percentage of the respondents $(46.7 \%)$ did not agree that the objectives met students' needs, deeming the objectives to be "poor", while 38.3\% thought they would mostly meet students' needs, and $15 \%$ said the objectives were "good" for meeting students' needs.

The third research question (To what extent is the textbook effective according to content?) was measured through five items in the questionnaire, and the responses are presented in Table 3. 
Table 3. Means, standard deviations, frequencies, and percentages for the items regarding (C) Content

\begin{tabular}{|c|c|c|c|c|c|c|}
\hline & ber & Good & Acceptable & Poor & Mean & Standard deviation \\
\hline 1 & $\mathrm{~F}$ & 19 & 28 & 12 & \multirow{3}{*}{2.12} & \multirow{3}{*}{0.721} \\
\hline & & & & & & \\
\hline & $\%$ & 31.7 & 46.7 & 20.0 & & \\
\hline \multirow[t]{3}{*}{2} & $\mathrm{~F}$ & 14 & 22 & 24 & \multirow{3}{*}{1.83} & \multirow{3}{*}{0.785} \\
\hline & & & & & & \\
\hline & $\%$ & 23.3 & 36.7 & 40.0 & & \\
\hline \multirow[t]{3}{*}{3} & $\bar{F}$ & 24 & 24 & 11 & \multirow{3}{*}{2.22} & \multirow{3}{*}{0.744} \\
\hline & & & & & & \\
\hline & $\%$ & 40.0 & 40.0 & 18.3 & & \\
\hline \multirow[t]{3}{*}{4} & F & 16 & 27 & 17 & \multirow{3}{*}{1.98} & \multirow{3}{*}{0.748} \\
\hline & & & & & & \\
\hline & $\%$ & 26.7 & 45.0 & 28.3 & & \\
\hline \multicolumn{2}{|c|}{ Overall } & $30.42 \%$ & $42.1 \%$ & $26.65 \%$ & 2.04 & \\
\hline
\end{tabular}

The content of the textbook was assessed by asking whether the content was interesting, the topics encouraged students to express their own views, the content used suitable language, and the content did not clash with local culture. The results of the evaluation survey are shown in Table 3.

For the first item, $46.7 \%$ of the teachers accepted the statement and moderately agreed that the content was interesting, while $31.7 \%$ totally agreed, saying that the content was interesting and "good"; however, $20 \%$ disagreed with this statement because they thought the content was "poor" and uninteresting.

Regarding the second item, asking whether the topics encouraged students to express their own views, the majority of respondents did not support this statement: about $40 \%$ thought the topics failed to encourage students to express their own views, $36.7 \%$ thought them "acceptable", and only $23.3 \%$ considered them to be effective.

Regarding the content using suitable language, most of the teachers (again, 40\%) totally agreed with this statement, another $40 \%$ found the language in the book "acceptable" too, and only $18.3 \%$ thought the content's language was totally unacceptable. Finally, the majority of the teachers $(45 \%)$ found the content "acceptable" for the local culture; $28 \%$ did not support this statement, believing that the content was not aligned with the local culture; and only $26.7 \%$ fully agreed with this statement.

The fourth research question ("To what extent is the textbook effective according to social and cultural contexts?") was measured through five items in the questionnaire, and the responses are presented in Table 4.

Table 4. Means, standard deviations, frequencies, and percentages for the items regarding (D) social and cultural contexts

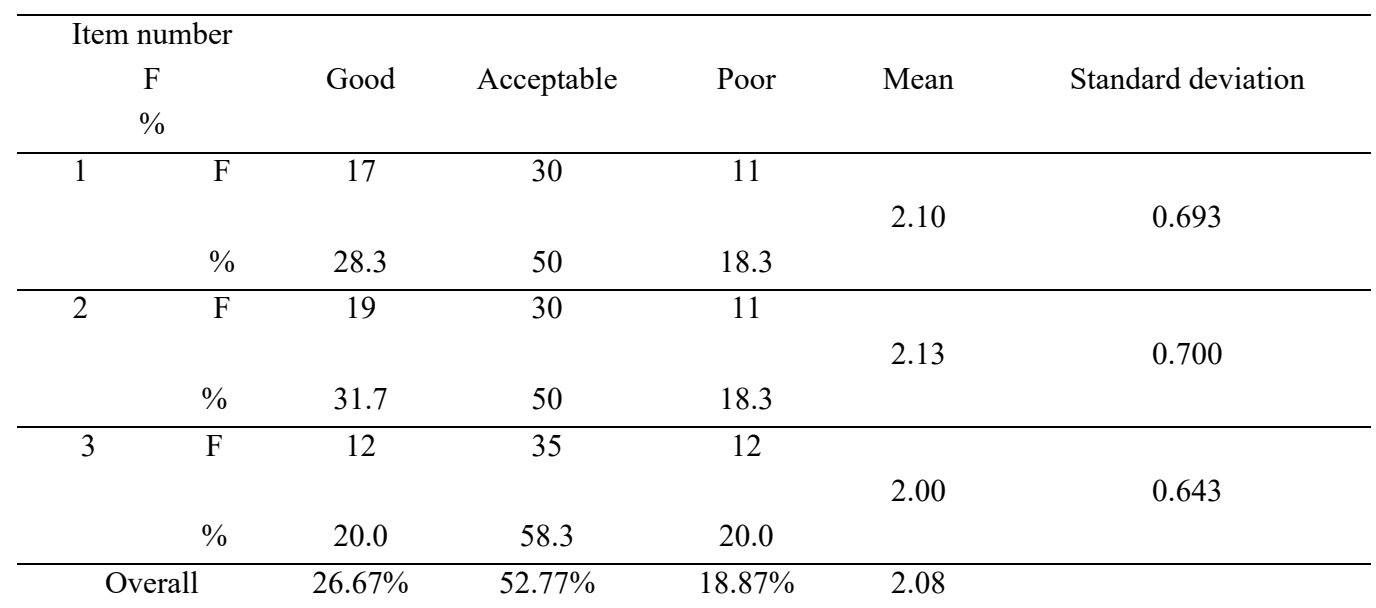

The social and cultural contexts of the textbook were determined by asking whether the content was comprehensible, displayed different traditions and customs, and fitted with the students' culture. The results of the evaluation survey are presented in Table 4. 
Regarding the first item, $50 \%$ of the respondents seemed to find that the social and cultural contexts in the textbook were comprehensible; $28 \%$ totally agreed with the statement; and only $19 \%$ did not support it, claiming that the social and cultural contexts were "poor" and incomprehensible.

Regarding the second item, about the content displaying different traditions and customs, $50 \%$ of teachers moderately agreed with this statement, finding the contexts "acceptable"; less than $32 \%$ fully supported the statement, asserting that the content effectively displayed different traditions and customs; and only $18.3 \%$ thought that the context poorly described different traditions and customs.

The last item regarding the social and cultural contexts in the topics concerned their fit with the students' culture, and the majority of the teachers $(58.3 \%)$ found them "acceptable", while the others were equally split between the "good" and "poor" options, showing that some agreed with the contexts and others did not.

The fifth research question concerning the extent to which the textbook effectively included tasks and activities was measured through five items in the questionnaire, and the responses are presented in Table 5.

Table 5. Means, standard deviations, frequencies, and percentages for the items regarding (E) tasks and activities

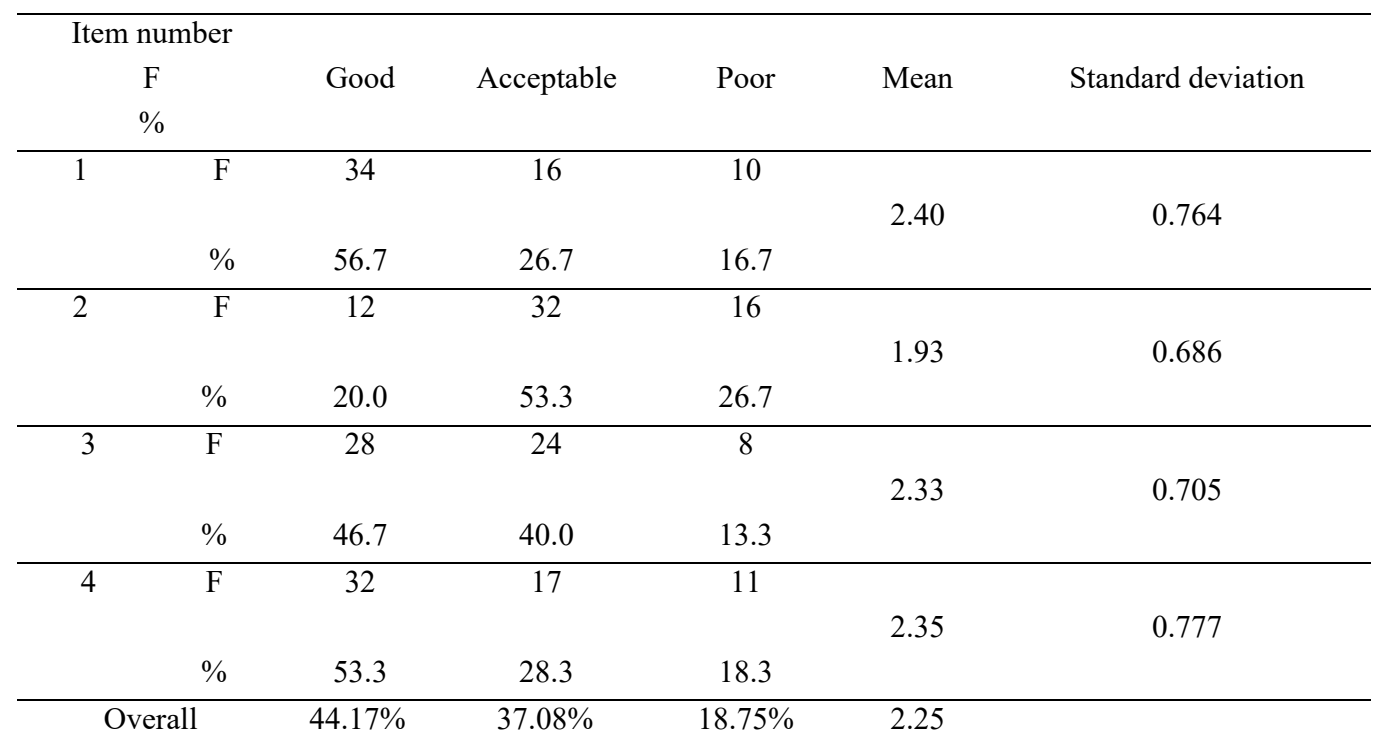

The tasks and activities in the textbook were evaluated by asking whether the activities had clear instructions, motivated students to participate, introduced authentic situations, and provided models for final tests. The results of the evaluation survey are shown in Table 5.

The majority of the teachers supported the first statement, with more than 56\% agreeing that the activities had clear instructions, while less than $27 \%$ thought the activities were "acceptable", and only $16.7 \%$ disagreed with the statement, claiming that the activities were "poor" and lacked clear instructions.

More than $50 \%$ of the teachers moderately agreed that the activities motivated students to participate, but less than $27 \%$ said the activities were "poor" and did not motivate students to participate, and only $20 \%$ fully agreed that they motivated participation.

The majority of the teachers agreed that the tasks introduced authentic situations, with more than $46 \%$ supporting the statement; $40 \%$ said the tasks were "acceptable" in introducing authentic situations, and only $13.3 \%$ claimed the tasks introduced authentic situations poorly.

Finally, more than $53 \%$ of the teachers agreed that the book provided "good" models for final tests, less than $29 \%$ said the textbook provided "acceptable" models, and around $18.3 \%$ thought that the textbook activities were "poor" and did not provide models for final tests.

The sixth research question, regarding the extent to which the textbook was effective for developing language skills, was divided into six categories (i.e., listening, speaking, reading, writing, grammar, and vocabulary).

\subsection{Listening}

The first category (listening) was measured through five items in the questionnaire, and the responses are presented in Table 6. 
Table 6. Means, standard deviations, frequencies, and percentages for the items regarding (F) language skills (listening)

\begin{tabular}{|c|c|c|c|c|c|c|}
\hline \multicolumn{2}{|c|}{$\begin{array}{c}\text { Item number } \\
\mathrm{F} \\
\%\end{array}$} & \multirow{2}{*}{$\begin{array}{c}\text { Good } \\
15\end{array}$} & \multirow{2}{*}{$\begin{array}{c}\text { Acceptable } \\
32\end{array}$} & \multirow{2}{*}{$\begin{array}{c}\text { Poor } \\
11\end{array}$} & \multirow{3}{*}{$\begin{array}{l}\text { Mean } \\
2.07\end{array}$} & \multirow{3}{*}{$\begin{array}{c}\text { Standard deviation } \\
0.672\end{array}$} \\
\hline 1 & $\mathrm{~F}$ & & & & & \\
\hline & & & & & & \\
\hline & $\%$ & 25.0 & 53.3 & 18.3 & & \\
\hline \multirow[t]{2}{*}{2} & $\mathrm{~F}$ & 12 & 28 & 20 & \multirow{2}{*}{1.87} & \multirow{2}{*}{0.724} \\
\hline & $\%$ & 20.0 & 46.7 & 33.3 & & \\
\hline \multirow[t]{2}{*}{3} & $\mathrm{~F}$ & 9 & 20 & 30 & \multirow[b]{2}{*}{1.64} & \multirow[b]{2}{*}{0.737} \\
\hline & $\%$ & 15.0 & 33.3 & 50.0 & & \\
\hline \multirow[t]{2}{*}{4} & $\mathrm{~F}$ & 28 & 21 & 11 & \multirow[b]{2}{*}{2.28} & \multirow[b]{2}{*}{0.761} \\
\hline & $\%$ & 46.7 & 35.0 & 18.3 & & \\
\hline & & $26.67 \%$ & $42.07 \%$ & $29.97 \%$ & 1.96 & \\
\hline
\end{tabular}

The listening skill development facilitated by the textbook was evaluated by asking whether the listening passages were adequate, the listening exercises focused on linguistic competence, the listening material was supplementary, and the listening material was authentic. The results of the evaluation survey are shown in Table 6.

Most of the teachers generally found the listening passages to be adequate, with more than $50 \%$ saying the listening passages were "acceptable"; however, 25\% thought the listening passages were "good" and less than $20 \%$ believed that they were inadequate.

Regarding the listening exercises, the majority of the teachers (46.7\%) found the focus on linguistic competence "acceptable", while $33.3 \%$ did not think they focused on linguistic competence, and only $15 \%$ strongly believed that they did so.

Regarding the listening material, $50 \%$ of the teachers did not agree with this item and said the listening material was not an effective supplement, while more than 33\% thought the listening material was "acceptable". Only $15 \%$ believed that the listening material was a "good" supplement.

The last statement in the section concerned the authenticity of the listening material. More than $46 \%$ thought it was "good" in this respect, 35\% found it "acceptable", and less than 19\% found the listening material inauthentic.

\subsection{Speaking}

The sixth research question, regarding the extent to which the textbook was effective for developing speaking skills, was measured through five items in the questionnaire, and the responses are presented in Table 7.

Table 7. Means, standard deviations, frequencies, and percentages for the items regarding (F) language skills (speaking)

\begin{tabular}{ccccccc}
\hline $\begin{array}{c}\text { Item number } \\
\text { F } \\
\%\end{array}$ & Good & Acceptable & Poor & Mean & Standard deviation \\
\hline 1 & $\mathrm{~F}$ & 18 & 26 & 16 & 2.03 & .758 \\
\hline 2 & $\%$ & 30.0 & 43.3 & 26.7 & & .723 \\
& $\mathrm{~F}$ & 17 & 29 & 14 & 2.05 & .751 \\
\hline 3 & $\mathrm{~F}$ & 28.3 & 48.3 & 23.3 & & .670 \\
\hline 4 & $\%$ & 41.7 & 38.3 & 18.3 & 2.24 & \\
\hline & $\mathrm{F}$ & 29 & 24 & 6 & 2.39 & \\
\hline
\end{tabular}


Regarding speaking skills, the questionnaire asked whether speaking activities motivated students to talk about their interests, encouraged students to become more confident, developed oral communication, and were authentic. The results of the evaluation survey are shown in Table 7.

The results for the first item showed that most of the teachers $(43 \%)$ considered that the speaking activities acceptably motivated students to talk about their interests; $30 \%$ fully agreed that they motivated students to talk about their interests, and less than $27 \%$ believed that they were "poor" in this respect.

Regarding the second item, over $48 \%$ of the respondents said that the speaking activities were "acceptable" for encouraging students to become more confident, $28 \%$ fully agreed that they encouraged students to become more confident, and less than $24 \%$ thought they were "poor" for encouraging confidence.

The majority of the teachers (41\%) agreed that speaking activities were "good" for developing oral communication, while $39 \%$ said the activities were "acceptable", and around $18.3 \%$ found them to be "poor" for developing oral communication.

Finally, the table shows that over $48 \%$ of the teachers agreed that the speaking activities were authentic, while $40 \%$ found them acceptably authentic, and only $10 \%$ thought they were "poor" in this respect.

\subsection{Reading}

The sixth research question, regarding the extent to which the textbook was effective for developing reading skills, was measured through five items in the questionnaire, and the responses are presented in Table 8.

Table 8. Means, standard deviations, frequencies, and percentages for the items regarding (F) language skills (reading)

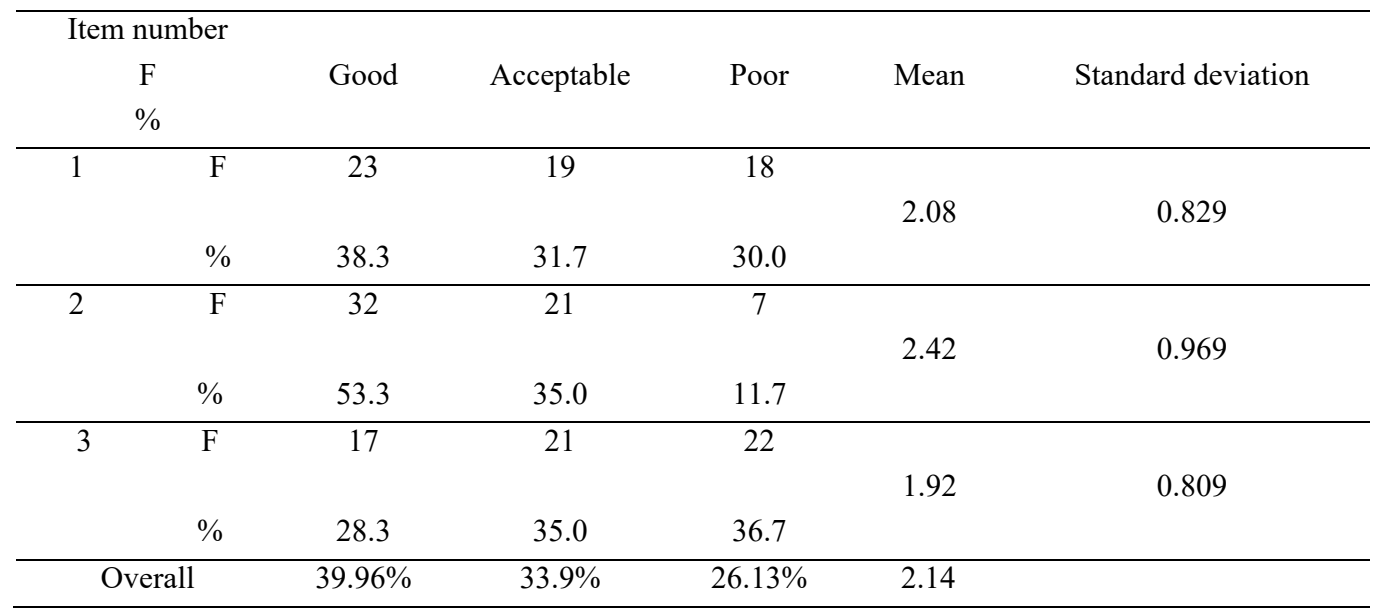

The extent to which the textbook helped to develop reading skills was evaluated by asking whether the reading material was appropriate for students' level and the reading passages were authentic and easy for most students to deal with. The results of the evaluation survey are shown in Table 8 .

The majority of the teachers (38\%) agreed that the reading material was "good" and highly appropriate for the students; less than $32 \%$ said it was "acceptable", due to the different levels of the students; and only $30 \%$ thought the material was "poor".

Regarding the second item, concerning the authenticity of the reading passages, over $53 \%$ of the respondents totally agreed with the statement, $35 \%$ thought it was "acceptable", and only $7 \%$ considered the passages to be "poor" and inauthentic.

The last item in the reading section asked whether the reading passages were easy for most students to deal with. The majority of the teachers with $37 \%$ saw the passages are difficult for most students to deal with, $35 \%$ thought they were "acceptable", and $28 \%$ believed that the reading passages were too easy for students.

\subsection{Writing}

The sixth research question asked about the extent to which the textbook was effective for developing writing skills, and this was measured through five items in the questionnaire. The responses are presented in Table 9. 
Table 9. Means, standard deviations, frequencies, and percentages for the items regarding (F) language skills (writing)

\begin{tabular}{|c|c|c|c|c|c|c|}
\hline \multicolumn{7}{|c|}{ Item number } \\
\hline \multirow{2}{*}{\multicolumn{2}{|c|}{$\begin{array}{l}\mathrm{F} \\
\%\end{array}$}} & Good & Acceptable & Poor & Mean & Standard deviation \\
\hline & & & & & & \\
\hline \multirow[t]{3}{*}{1} & $\mathrm{~F}$ & 14 & 25 & 21 & \multirow{3}{*}{1.88} & \multirow{3}{*}{0.761} \\
\hline & & & & & & \\
\hline & $\%$ & 23.3 & 41.7 & 35.0 & & \\
\hline \multirow[t]{3}{*}{2} & $\mathrm{~F}$ & 8 & 22 & 30 & \multirow{3}{*}{1.63} & \multirow{3}{*}{0.712} \\
\hline & & & & & & \\
\hline & $\%$ & 13.3 & 36.7 & 50.0 & & \\
\hline \multirow[t]{3}{*}{3} & $\mathrm{~F}$ & 16 & 24 & 19 & \multirow{3}{*}{1.95} & \multirow{3}{*}{0.775} \\
\hline & & & & & & \\
\hline & $\%$ & 26.7 & 40.0 & 31.7 & & \\
\hline \multicolumn{2}{|c|}{ Overall } & $21.1 \%$ & $39.46 \%$ & $38.9 \%$ & 1.82 & \\
\hline
\end{tabular}

The extent to which the textbook helped to develop writing skills was evaluated by asking whether the writing tasks were interesting, appropriate to the students' level, and provided different types of writing tasks. The results of the evaluation survey are shown in Table 9.

Over $41 \%$ of the teachers found the writing tasks "acceptable", while $35 \%$ thought they were boring, and less than $24 \%$ found them "good" and interesting.

The second item concerned the appropriateness of the writing tasks for the students' level: $50 \%$ of the teachers considered the tasks too difficult for the students' level, $36 \%$ found them "acceptable" and appropriate, and only $14 \%$ fully supported the statement.

The last item in the writing section concerned the provision of different types of writing tasks. Around $40 \%$ of the respondents found the provision of writing tasks "acceptable", $31 \%$ considered that the textbook provided insufficiently different types of writing tasks, and less than $27 \%$ were fully satisfied with the provision of writing tasks.

\subsection{Grammar}

The sixth research question concerned the extent to which the textbook was effective for developing grammar skills. This was measured through five items in the questionnaire, and the responses are presented in Table 10.

Table 10. Means, standard deviations, frequencies, and percentages for the items regarding (F) language skills (grammar)

\begin{tabular}{|c|c|c|c|c|c|c|}
\hline & ber & Good & Acceptable & Poor & Mean & Standard deviation \\
\hline 1 & $\mathrm{~F}$ & 18 & 32 & 10 & \multirow{3}{*}{2.13} & \multirow{3}{*}{0.676} \\
\hline & & & & & & \\
\hline & $\%$ & 30.0 & 53.3 & 16.7 & & \\
\hline \multirow[t]{3}{*}{2} & $\bar{F}$ & 14 & 24 & 22 & \multirow{3}{*}{1.87} & \multirow{3}{*}{0.769} \\
\hline & & & & & & \\
\hline & $\%$ & 23.3 & 40.0 & 36.7 & & \\
\hline \multirow[t]{3}{*}{3} & $\mathrm{~F}$ & 26 & 20 & 13 & \multirow{3}{*}{2.22} & \multirow{3}{*}{0.789} \\
\hline & & & & & & \\
\hline & $\%$ & 43.3 & 33.3 & 21.7 & & \\
\hline & & $32.2 \%$ & $42.2 \%$ & $25.03 \%$ & 2.07 & \\
\hline
\end{tabular}

The extent to which the textbook helped to develop grammar skills was evaluated by asking whether the grammar examples were appropriate to the students' level, the grammar exercises were sufficient, and the grammar points were presented with helpful examples and explanations. The results of the evaluation survey are shown in Table 10.

Over $53 \%$ of the respondents claimed that that grammar examples were "acceptable" for the students' level, $30 \%$ totally agreed that the examples were "good" and appropriate to their level, and less than $17 \%$ insisted that the 
grammar examples were difficult and inappropriate for the students' level.

Regarding the provision of grammar exercises, $40 \%$ found it "acceptable", less than $37 \%$ deemed the exercises to be inadequate, but over $23 \%$ considered them to be perfectly sufficient.

Finally, in response to the question asking whether the grammar points were presented with helpful examples and explanations, $43 \%$ of the teachers felt that they made it easy to teach grammar, because the grammar points were accompanied by plenty of examples and explanations; however, $34 \%$ found the grammar points "acceptable" and $22 \%$ thought that the many points, examples, and explanations would be difficult for students to understand and would take time to absorb.

\subsection{Vocabulary}

Finally, the extent to which the textbook was effective for developing vocabulary skills was measured through five items in the questionnaire, and the responses are presented in Table 11.

Table 11. Means, standard deviations, frequencies, and percentages for the items regarding (F) language skills (vocabulary)

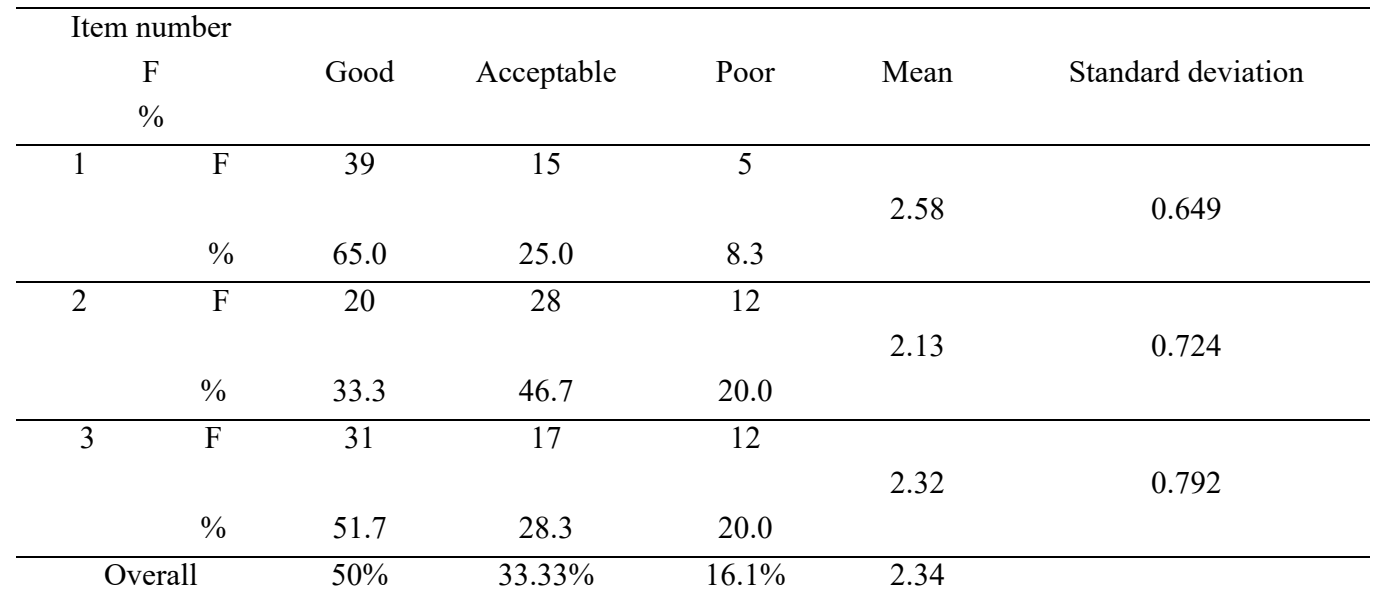

The vocabulary skills facilitated by the textbook were evaluated by asking whether the vocabulary exercises were rich, the vocabulary lists were appropriate to the students' level, and a list of vocabulary items was provided at the end of the textbook. The results of the evaluation survey are shown in Table 11.

Around $65 \%$ of the teachers agreed that the vocabulary exercises were rich, almost $25 \%$ found them "acceptable", and only $8 \%$ considered them to be "poor".

The majority of the teachers (46\%) believed vocabulary lists were "acceptable" in terms of their appropriateness for the students' level, more than $33 \%$ agreed that they were highly satisfactory, and only $20 \%$ considered them inappropriate for the students' level.

Regarding the list of vocabulary items provided at the end of the textbook, over $51 \%$ of the teachers agreed with the statement, because a list of vocabulary items was provided at the end of the textbook. More than $28 \%$ of them accepted the statement, but $20 \%$ did not agree.

\section{Conclusions and Recommendations}

This section consists of four sections: summary, conclusion, recommendations, and suggestions. After summarizing all the content of this paper, the author presents an overview of the research hypotheses, then makes recommendations and, finally, offers suggestions for further study.

\subsection{Summary}

The purpose of this study was to evaluate the quality of the English textbook Traveller 4 for use in secondary schools in Riyadh City. The review of the literature relating to textbook evaluation considered various theoretical and empirical studies that have contributed to the field of educational materials evaluation.

The research used a descriptive research model to assess an English textbook used in the second grade of secondary schools in Riyadh City and collected data to address the extent to which the textbook was effective according to the following categories: the general appearance and design, objectives, content, social and cultural contexts, tasks and activities, and language skill development. A survey questionnaire was used to elicit the perspectives of English language teachers, teaching in government high schools in Riyadh City, regarding the 
textbook's general appearance and design, objectives, content, social and cultural contexts, tasks and activities, and usefulness for developing language skills. The findings of the research revealed important points that relate to the characteristics of a good textbook, showing the textbook's strengths and weaknesses, and indicating certain desirable modifications of the book.

The general appearance of the textbook was acceptable for the majority of the teachers. Over $43 \%$ of them found the general appearance acceptable. The objectives of the textbook were also considered acceptable by most teachers, and the content of the textbook was also acceptable to teachers, with over $42 \%$ finding all the items in this category acceptable, except for the topics' inability to encourage students to express their own views: $40 \%$ did not find the content acceptable in this respect. Over $52 \%$ of the teachers found the social and cultural aspects to be acceptable. The tasks and activities were considered particularly "good" by some teachers, but overall, most teachers found the aspects in this section to be acceptable.

The language skills section contained six subsections: listening, speaking, reading, writing, grammar, and vocabulary. For listening skills, the majority of the teachers found most aspects acceptable except the supplementary listening material, which $50 \%$ considered to be inadequate. Regarding speaking skills, most of the teachers $(42 \%)$ found all the items acceptable. Concerning reading skills, the teachers found most acceptable, and some reading passages are easy for most students to deal with and they likely did not agree on statement. For writing skills, over $39 \%$ found the content acceptable, except the writing tasks' appropriateness for the students' level, with $50 \%$ finding it unacceptable. Regarding the grammar section, the majority of the teachers $(42 \%)$ considered all the items to be acceptable, and for the vocabulary section, the majority of teachers $(50 \%)$ supported all the aspects.

\subsection{Conclusions}

According to the teachers' perceptions, Traveller 4 was acceptable for second grade high school in Riyadh City in terms of its general appearance and design, objectives, content, social and cultural contexts, tasks and activities, and language skills. In the current study, only male teachers teaching in government high schools in Riyadh City evaluated the six categories of Traveller 4. The results of this study could guide textbook designers and teachers in designing, selecting, and evaluating the textbooks.

\subsection{Recommendations}

The recommendations of this study suggest the following modifications to the book shortly. First, although the textbook is a relatively new series, the Ministry of Education in Saudi Arabia may consider adding more objectives to ensure that they are achieved at the end of the semester. Second, the topics should attract more students to express their own views. Furthermore, listening skills should be supplemented by its tools. Finally, writing tasks should be interesting and appropriate to the students' level.

\subsection{Suggestions}

Further research is suggested:

1. Comparing this textbook with other books used in different cities in Saudi Arabia.

2. Evaluating the quality and effectiveness of other English language textbooks, either in Riyadh city or other cities in Saudi Arabia.

3. Evaluating a similar English textbook used in girls' schools from female teachers' perspectives.

\section{References}

AI-Hamid, M. (1998). Curriculum development between fixed and variable. Retrieved from https://search.mandumah.com/Record/292812

Aljaser, Afaf M. (1989). An Analysis of the English Language Textbooks Taught at the First Year Boy and Girls' Secondary Schools: A Comparative Study. Unpublished MA thesis, King Saud University. Riyadh, Saudi Arabia.

Cunningsworth, A. (1995). Choosing your course book. Oxford: Heinemann Publishers Ltd.

Development between static and dynamic change. Al-Marrefah, 35, 102-105.

Development of education in the Kingdom of Saudi Arabia: National Report. Riyadh.

Documentation: A Semi- Annual Bulletin, N. 36, 60-72.

Ellis, R. (1997). The Empirical Evaluation of Language Teaching Materials. ELT J., 51(1), 36-42. https://doi.org/10.1093/elt/51.1.36 
Eriksoussy, Zubaidah M. (1993). Evaluating the English Language Textbook Studied at the First Year Intermediate Schools in Saudi Arabia. Unpublished MA thesis, King Saud University. Riyadh, Saudi Arabia.

Habtoor, H. A. (2012). English for Specific Purpose Textbook in EFL Milieu: An Instructor's Perspective Evaluation. International Journal of Linguistics, 4(3). https://doi.org/10.5296/ijl.v4i3.1732

Hutchinson, T. (1987). What is underneath? An interactive view of the material evaluation. In L. E Sheldon (Ed.), ELT textbooks and materials: Problems in evaluation and development (pp. 37-44), Oxford: Modern English Publications.

Litz, D. R. A. (2005). Textbook evaluation and ELT management: A South Korean case study. Asian EFL Journal, 35, 10. Retrieved from https:/www.asian-efl-journal.com/Litz_thesis.pdf

Patton, M. (1990). Qualitative evaluation and research methods. Newbury Park, CA. https://doi.org/10.1002/nur.4770140111

Richards, J. C. (2001). The Role of text Books in a Language Program. Cambridge University Press. Saudi Arabia: Ministry of Education.

Tok, H. (2010). TEFL textbook evaluation: From teachers' perspectives. Educational Research and Review, 5(9), 508-517. Retrieved from https://www.academicjournals.org/app/webroot/article/article1379623669_Hidayet.pdf

Tomlinson, B. (2003). Developing materials for language teaching. London: Bloomsbury Academic. https://doi.org/10.5040/9781474211826.0005

Weir, C. J., \& Roberts, J. (1994). Evaluation in ELT. Oxford: Blackwell. 


\section{Appendix}

A- General Appearance and Design

\begin{tabular}{l} 
1. The book is attractive. \\
2. The book's size is appropriate \\
3. The book has a title at the beginning of each subject \\
4. The illustrations are simple \\
5. The illustrations are colored \\
\hline B- Objectives \\
\hline 1. The objectives are clear. \\
2. The objectives are measurable. \\
3. The objectives are achievable \\
4. The objectives are meet students' needs \\
\hline C- Content
\end{tabular}

1. The content of the textbook is interesting

2. The topics encourage students to express their own views

3. The content uses suitable language

4. The content does not clash with local culture

D- Social and Cultural Contexts

Good Acceptable Poor

1. The social and cultural contexts in the textbook are comprehensible.

2. The content displays different traditions and customs

3. The topics of the content fit with the students' culture.

$$
\text { E- Tasks and Activities }
$$

1.The activities have clear instructions

2.The tasks introduce authentic situations

3.The activities motivate students to participate

4. The book provides models for final tests

F- Language Skills

Good Acceptable Poor

1. Listening

a. The listening passages are adequate

b. The listening exercises focus on linguistic competence

c. Listening material is supplementary

d. Listening material is authentic

\footnotetext{
2. Speaking

a. Speaking activities motivate students to talk about their interests

b. Speaking activities encourage students to become more confident

c. Speaking activities develop oral communication
} 
d. The speaking activities are authentic

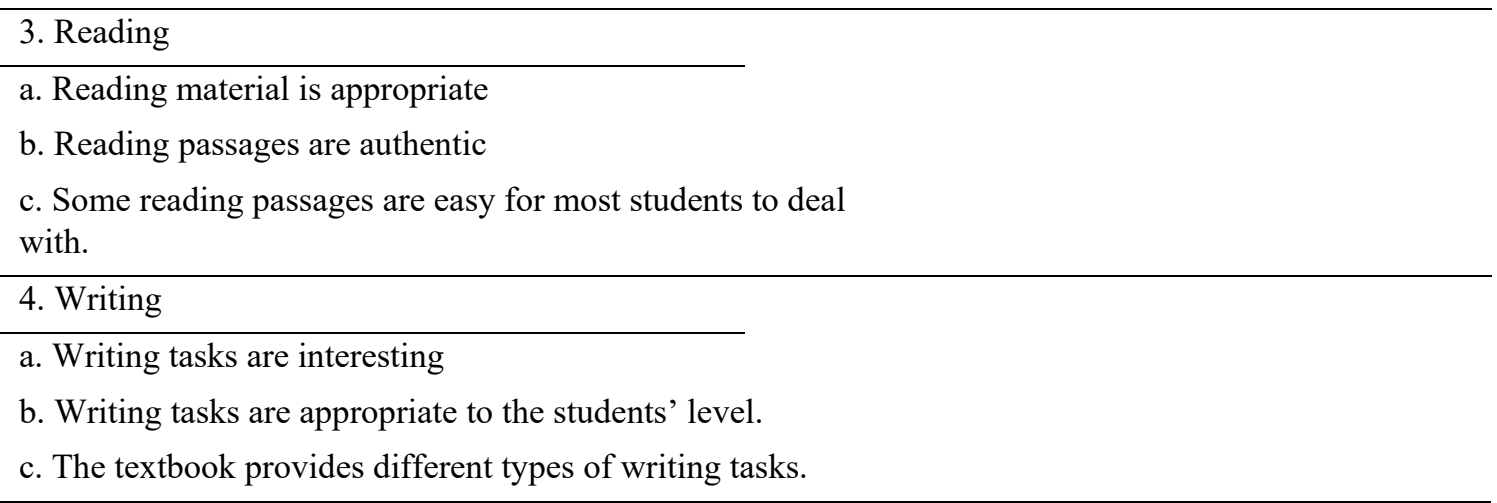

\section{Copyrights}

Copyright for this article is retained by the author(s), with first publication rights granted to the journal.

This is an open-access article distributed under the terms and conditions of the Creative Commons Attribution license (http://creativecommons.org/licenses/by/4.0/). 